\title{
Gene Carriers and Transfection Systems Used in the Recombination of Dendritic Cells for Effective Cancer Immunotherapy
}

\author{
Yu-Zhe Chen, ${ }^{1}$ Xing-Lei Yao, ${ }^{1}$ Yasuhiko Tabata, ${ }^{2}$ Shinsaku Nakagawa, ${ }^{3}$ and Jian-Qing Gao ${ }^{1}$ \\ ${ }^{1}$ Institute of Pharmaceutics, College of Pharmaceutical Sciences, Zhejiang University, Hangzhou, Zhejiang 310058, China \\ ${ }^{2}$ Department of Biomaterials, Field of Tissue Engineering, Institute for Frontier Medical Sciences, Kyoto University, 53 Kawanara-cho, \\ Shogoin, Sakyo-ku, Kyoto 606-8507, Japan \\ ${ }^{3}$ Department of Biotechnology and Therapeutics, Graduate School of Pharmaceutical Sciences, Osaka University, 1-6 Yamadaoka, \\ Suita, Osaka 565-0871, Japan \\ Correspondence should be addressed to Jian-Qing Gao, gaojianqing1029@yahoo.com.cn
}

Received 1 July 2010; Accepted 28 October 2010

Academic Editor: Robert E. Cone

Copyright (๑) 2010 Yu-Zhe Chen et al. This is an open access article distributed under the Creative Commons Attribution License, which permits unrestricted use, distribution, and reproduction in any medium, provided the original work is properly cited.

Dendritic cells (DCs) are the most potent antigen-presenting cells. They play a vital role in the initiation of immune response by presenting antigens to $\mathrm{T}$ cells and followed by induction of T-cell response. Reported research in animal studies indicated that vaccine immunity could be a promising alternative therapy for cancer patients. However, broad clinical utility has not been achieved yet, owing to the low transfection efficiency of DCs. Therefore, it is essential to improve the transfection efficiency of DC-based vaccination in immunotherapy. In several studies, DCs were genetically engineered by tumor-associated antigens or by immune molecules such as costimulatory molecules, cytokines, and chemokines. Encouraging results have been achieved in cancer treatment using various animal models. This paper describes the recent progress in gene delivery systems including viral vectors and nonviral carriers for DC-based genetically engineered vaccines. The reverse and three-dimensional transfection systems developed in DCs are also discussed.

\section{Introduction}

Cancer is a leading cause of death worldwide. Although progress has been made in cancer therapy with conventional treatment modalities, such as surgery, chemotherapy, and radiotherapy over the last several decades [1], the total number of cancer-related deaths is still increasing. Therefore, there is an urgent requirement to develop novel therapies for the treatment of cancer. With the rapid developments in the fields of immunology and cancer biology, immunotherapy is expected to play a key role in next-generation cancer treatment. The goal of immunotherapy is to promote the patient's own immune system to kill cancer cells instead of using external helpers, that is, surgery or medicine. To induce a specific immune response against cancers, researchers have designed a variety of antitumor vaccines based on the molecular identities of tumor-associated antigens (TAAs).
Recent findings from this line of research suggest that immunotherapy strategies are feasible and promising [2-4].

DCs are professional and the most potent antigenpresenting cells (APCs) of T-cell special responses, which play an important role in initiating and regulating adaptive immune responses [5]. The major function of DCs in immune system is capturing exogenous and endogenous antigens when infection or cancer occurs, and then presenting the antigens to $\mathrm{T}$ cells via major histocompatibility complex (MHC) molecules [6]. Moreover, DCs are also involved in regulating immune tolerance and clonal selection $[7,8]$. In 1990, it was firstly reported that injection of DCs with protein antigens ex vivo could prime antigenspecific response in animal model [9]. After that, several studies demonstrated that DCs pulsed with TAAs could produce significant therapeutic immunity to tumors with low toxicity. Because DCs could manipulate the immune 
system by enhancing specific responses to infectious diseases and cancer, DCs networking system became an attractive approach in cancer therapy $[10,11]$.

The results of early studies in animal models and some preclinical trials indicated that TAA-presenting DC might be a promising treatment for cancer. However, it is difficult to induce long-term tumor-specific immune response in humans. This may be due to the fact that most TAAs are selfantigens, which make cancer cells bypass normal immune protective mechanisms. Therefore, in order to overcome tolerance against self-antigens, it is necessary for an efficient vaccine to induce autoimmune responses [12]. Additionally, the suppressive mechanisms in tumor microenvironment can also inhibit immune response to malignant cells [13]. Hence, designing and developing an efficient and long-term DC vaccine, which could specifically target cancer cells, is urgently needed. Subsequent studies have shown that vaccination using DCs in vitro transferred with transgene encoding TAAs or immunomodulatory proteins are more efficient than using cells directly pulsed with protein antigens, tumor peptides, lysates, or RNA [14].

This paper focuses on the recent findings in DC vaccinations genetically engineered by recombination biotechnology via different vectors and overviews the development of gene delivery systems for DCs.

\section{Biological Characteristics of DCs and the Process of DC-Mediated Immune Response}

The DCs are generated from $\mathrm{CD}_{3} 4^{+}$bone marrow stem cells and from DC precursors in the peripheral blood. The concentration of DCs in normal tissue and blood is very low, which makes it difficult to isolate DCs directly from peripheral blood and bone marrow. Currently, the prevalent procedure is to differentiate the monocytes from peripheral blood and bone marrow to DCs with the help of leukapheresis technology and stimulation by cytokines [15].

According to biological properties of DCs, they could be divided into three major groups: plasmacytoid DCs (pDCs), inflammatory DCs (iDCs), and conventional DCs (cDCs) $[16,17]$. cDCs are also named myeloid DC (mDCs) owing to their typical form and function [18]. They can be further divided into lymphoid-tissue-resident DCs (splenic, thymic DCs, etc.) and migratory DCs (Langerhans cells, dermal DCs, etc.) [19]. Unlike migratory DCs, which migrate through the lymph, lymphoid-tissue-resident DCs are located mostly at lymphoid tissues to collect and present antigens [20]. Both of the mDCs can be further classified based on the levels of phenotype protein expression and function. For example, $\mathrm{CD} 8^{+}$and $\mathrm{CD} 4^{+} \mathrm{mDCs}$, which were found to preferentially express MHC I and II, respectively, induce different types of T-cell responses $[21,22]$.

On the other hand, on the basis of the different phenotype and surface antigens, DCs could also be divided into immature and mature DCs. The term "immature" refers to DCs with the phenotypic features of low expression of MHC II and molecules such as CD86. In contrast, mature
DCs are characterized by high expression of MHC II and T-cell costimulatory molecules such as CD40, CD80, CD83, and CD86 [23-25]. Under pathologic conditions, DCs are stimulated by microbes, products of damaged tissues, cells of the innate or adaptive immune system, and inflammatory cytokines. These endogenous and exogenous antigens are taken up by DCs through the specialized endocytic system, which is mediated by a variety of receptors such as Toll-like receptors (TLRs) [4, 26], nucleotide-binding, and oligomerization domain proteins (NODs) [27, 28]. Then DCs undergo a complex process of activation making immature antigen-capturing DCs change into APCs. The process is characterized by extended dendrites of DC's external form. As a result, their cellular motility to migrate to the draining lymph node is increased [29]. Meanwhile, their surface costimulatory molecules such as CD40, CD80, and CD86 are upregulated [30-32], and MHC molecules are expressed on the surface of cells [33]. One of the major functions of DCs in immune system is capturing and presenting the antigen to $\mathrm{T}$ cells via $\mathrm{MHC}$ molecules. When the antigen is presented by APCs through MHC I, which interacts with $\mathrm{CD} 8^{+} \mathrm{T}$ cells, the activated $\mathrm{T}$ cells could differentiate into cytotoxic T lymphocytes (CTLs). Activation of $\mathrm{CD}^{+} \mathrm{T}$ cells occurs with the help of MHC II. After activation, the $\mathrm{CD}^{+} \mathrm{T}$ cells differentiate into T-helper 1 (Th1) and T-helper 2 (Th2) cells, which are involved in inducing macrophages and B-cells responses [34, 35]. CTLs are the major killers of tumor cells; they accomplish the killing with the help of $\mathrm{CD}^{+} \mathrm{T}$ cells, which can induce potential long-term $\mathrm{CD}^{+} \mathrm{T}$-cell responses by producing various cytokines $[36,37]$.

As it is well known that intracellular endogenous antigens and exogenous antigens are presented in MHC I and MHC II by DCs, respectively [38], the strategy for DCbased vaccines in cancer immunotherapy is to make DCs cross-presentation. This can present MHC I to CTLs using internalized antigens generated from exogenous sources. Through this process, TAAs can be presented by the DC to both $\mathrm{CD}^{+}$and $\mathrm{CD}^{+} \mathrm{T}$ cells (in MHC I), and a broad and strong immune response against tumor could be induced $[16,39]$.

\section{Methods Used in Genetically Engineered DCs}

3.1. Modified/Pulsed Methods. It is generally believed that, the direct presentation of TAAs to CD8 ${ }^{+}$CTLs (e.g., direct administration of tumor peptides) is most tolerogenic [40, 41]. Several evidences showed that the differentiation and maturation of DCs were suppressed by cytokines existing in the tumor microenvironment. Since DCs play a crucial role in inducing antigen-specific T-cell responses, it is important to deliver tumor antigens with $\mathrm{CD}^{+}$and $\mathrm{CD} 4^{+} \mathrm{T}$-cell epitopes to DCs. There are several strategies to induce DCs to present exogenous antigens on MHC I molecules [42].

According to the mechanism of MHC-mediated antigen presentation, early researchers tried to pulse DCs directly with tumor-specific peptides. Synthetic MHC I-binding peptides have been used in DC-based vaccination. The 
TAAs, which were derived from MHC I-binding peptides, including melanoma-related antigens $[43,44]$, carcinoembryonic antigen (CEA) $[45,46]$, folate binding protein (FBP) $[47,48]$, prostate-specific membrane antigen (PMSA) [49, 50], and Mucin 1 (MUC-1) [27, 51, 52], were firstly used to modify DCs. This strategy was easy to perform and was shown to be successful in some animal studies and clinical trials. Further development in using Tat peptide, which is from transduction domain of Human Immunodeficiency Virus (HIV), makes this strategy more effective $[46,53]$. However, as this approach was mainly based on specific MHC I-restricted peptides, the importance of MHC IIrestricted T-helper $(\mathrm{Th})$ cells in mediating response $\left(\mathrm{CD} 4^{+}\right.$ $\mathrm{T}$ ) and accelerating immune responses [54] was not fully considered.

Because of the limitations of using one single TAA peptide to modify DCs, researchers began to design vaccination utilizing DCs pulsed with whole tumor lysates. In this approach, as the tumor cell preparations contain lots of relevant antigens, broad-spectrum TAAs including unknown ones were presented to $\mathrm{T}$ cells and this induced an immune response. The advantages of this method include (1) presenting multiple peptides and epitopes to T cells to induce CTL response; (2) generating both $\mathrm{CD} 8^{+}$response and $\mathrm{CD}^{+}$helper $\mathrm{T}$-cell response, which help to induce macrophages and $\mathrm{B}$-cell response as well as prolonging the CTLs response; (3) reducing the workload of discovering and preparing appropriate peptides and epitopes required to be presented on DCs and then to be identified by T cells; (4) probably generating tumor lysate-specific memory $\mathrm{T}$ cells [55]. The results in animal models and in clinic trials using total tumor lysate approaches have been demonstrated to be highly effective and have low toxicity in a variety of cancers $[56,57]$. It was further observed that DCs pulsed with apoptotic tumor cell preparation showed a more pronounced effect in activating $\mathrm{T}$ cells [58]. The main limitation of this method is the limited amount of patient tumor cells we could collect, making the preparation work difficult. Another problem is that the presence of many irrelevant antigens in tumor cell preparations could cause autoimmune responses.

Since the early reports on transfection with RNA showed strong immune response against tumor [59, 60], mRNApulsed DCs have become a research hotspot these days. Because RNA-based vaccines have many advantages including easily preparation, low price, specificity, control, and no risk of incorporation into the host genome [61]. DCs were transfected with tumor mRNA encoding TAA or epitopes by using carriers [61, 62] or electroporation [63, 64]. This can also induce tumor-specific immunity in vitro. By transfection with RNA, DCs can express specific or total antigen on their surface and finally present them to $\mathrm{T}$ cells [65]. In addition, using mRNA could be a promising therapy for the patients who have only few available tumor cells for mRNA preparation, because mRNA could be produced in large amounts through noninvasive biopsy procedures [66]. Recent studies indicated that mRNA has been used not only as a source of antigen, but also as a way to stimulate DC to produce immunostimulatory molecules [67]. The main limitations of using $\mathrm{mRNA}$, however are difficulty in manipulation, having lower transfer efficiency and shorter lifespan (degradated by RNases rapidly) [68].

3.2. Modified/Pulsed Methods. To enhance DCs antitumor efficiency, the delivery of DNA encoding TAAs, immunostimulatory molecules, cytokines, chemokines, and other stimuli has been developed in the recent years. Compared with tumor antigen loading strategies described previously, genetical engineering of DCs has some special advantages, which include: (1) bypassing the work of understanding the complex intracellular process of MHC-mediated presentation; (2) achieving the purpose of cross presentation to induce a robust immune response; (3) showing a longterm antigen expression; (4) significantly reducing the autoimmune response; (5) easier preparation; (6) stability in transduction process. However, there are also some limitations in DNA-based DC vaccination. Immunotherapy using DCs transferred by viral vectors may induce an autoimmune response and mutation. Nonviral transfer shows very low transfer efficiency. DNA strategy also has its intrinsic problems such as persisting expression and genome incorporation risk. These problems are needed to be considered and solved before it becomes a better application.

To date, various vehicles and methods have been developed for gene transfer of DCs. Vehicles can be divided into viral vectors and nonviral carriers. And there are also some other transfection methods such as ultrasound and electroporation. By using different carries and transfection methods, the transduction efficiency and the preclinic trial results are different $[69,70]$. After long-term experiments in vitro and in vivo, an increasing number of scholars think that the transduction of DCs using vehicles shows more advantages than using naked DNA alone. The major advantage of using viral vectors is their high efficiency in the transfection, which induced high protein expression levels. The limitations of this method are immune and mutation risk. For example, the host cells might express the viral proteins, and thereby might induce immunologic interference. In contrast, the nonviral strategy, which is regarded as a safer alternative to virus-mediated transduction, is considered to be promising treatment in clinic. Nonviral carriers could overcome the problems caused by viral vectors. In addition, nonviral carriers were more stable and controllable in preparation and application. The risk of virus-associated recombination mutation in host genome could be avoided. It makes DNA vaccines feasible in clinical application. But the major limitations of nonviral carriers are low efficiency in transfection and low levels of protein expression. It needs to be optimized by the carriers modified system. The mechanisms of transfection using viral vectors and nonviral carriers are shown below (Figures 1 and 2).

3.2.1. DCs Transferred by Viral Vectors. In contrast with direct viral vaccine, DCs transferred by viral vectors in vitro would reduce the production of certain type of antibodies, which may cause side effects and would finally reduce the effectiveness of cancer therapy in clinic [71]. The viruses 


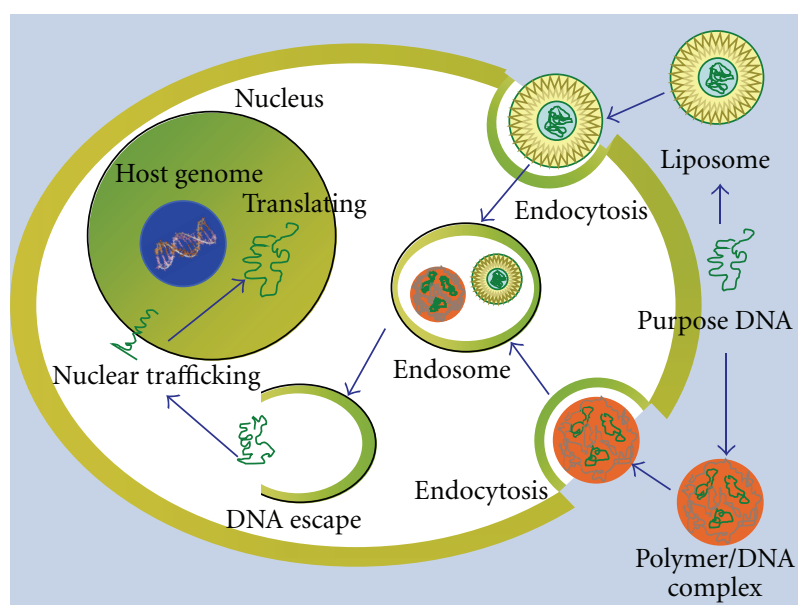

FIgURE 1: The mechanism of transfection using nonviral carriers.

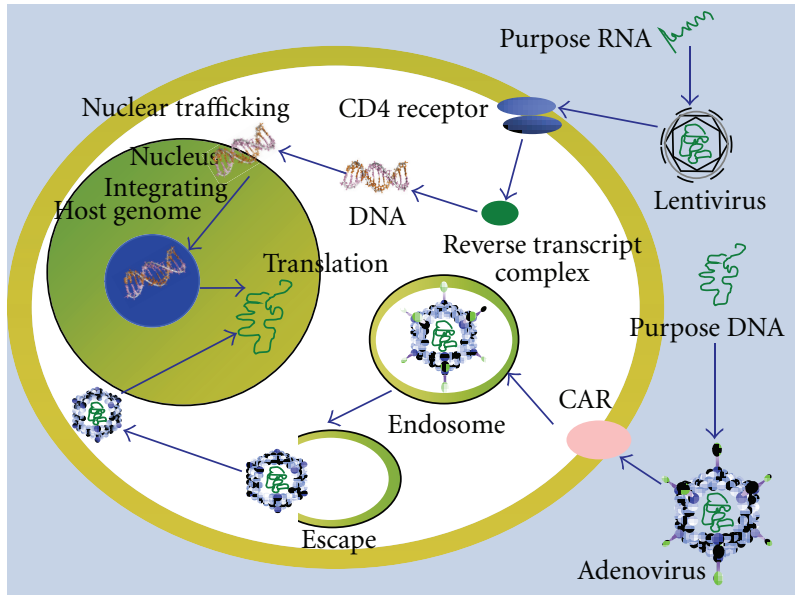

FIGURE 2: The mechanism of transfection using viral vectors. employed as gene vectors include adenoviruses (Ad), adenoassociated viruses (AAV), retrovirus, lentivirus, and other viruses. These viruses are all deleted critical genes needed for their reproduction. And then, they are inserted with purpose genes such as genes encoding TAAs. Recombinant viral vectors might be the most attractive gene transduction vehicles because of their high transfection efficiency, although they are more immunogenic than nonviral carriers in clinical applications [72]. To minimize the risk of specific immunity and to boost the clinical antitumor response, several improvements in viral strategies have been developed, such as replacing the genes required for viral replication with the helper plasmids and modifying the genome of viral capsid [73]. However, to date, there is not a perfect treatment for tumor by using viral vectors-transferred DCs, as the application of viruses in vivo could destroy the antigenpresenting function of DCs.

Adenovirus. Adenovirus (Ad), which is nonenveloped and medium-sized (90-100 nm) viruses, has a double-stranded linear DNA genome. The adenoviral genome comprises four early (E1, E2, E3, and E4), four intermediate, and one late transcriptional units. To use Ad as a gene-transferring vector, the E1 gene, which contributes to reproduction, must be deleted. Ad vectors (AdVs) are based on substitution of the E1 region by the therapeutic gene. AdVs are widely used for basic and clinical research because of their high transduction efficiency [74-76]. The primary and secondary binding receptors of AdVs, Coxsackie adenovirus receptor (CAR), and V-integrin play important roles in mediating the uptake of immature DCs. AdVs can consistently induce potent presentation of both MHC class I and class IIrestricted epitopes. Several studies demonstrated that using AdVs could be regarded as a valuable gene delivery system even in clinical application, for example, serotype 5 (rAd5) [77-80]. Interactions between AdVs and DCs were also investigated recently. These include virus-mediated DC maturation, antigen processing machinery $(\mathrm{APM})$ regulation and T-cell activation. It was observed that the phenotype and cytokine profile of DC transduced with Ads changed $[81,82]$, some selected modification of DCs by Ads are listed in Table 1. These results provide the evidence for the designing human cancer vaccines.

Retrovirus and Lentivirus. Retrovirus is a single-stranded (ss) RNA virus, which is replicated from RNA to DNA by the revertase. Then the produced DNA is integrated into the host's genome by an integrase enzyme. With the replication of host genome, the viruses reproduce as part of the host's DNA. Retroviruses also attract the DC researchers these years for their transduction capacity of bone marrow-derived DCs (BMDCs) and cord blood-derived DCs to keep their differentiation $[93,94]$. The advantages of retroviral vectors used as transduction vehicles include the stable expression of full-length proteins and less immunologic responses against viral antigens because their structural proteins are not expressed [68]. However, most retroviruses are difficult to transfect nondividing cells such as mature DCs. This disadvantage limits the application of retroviruses in clinic.

Lentiviruses derived from HIVs belong to retroviruses family. It is easier for the lentivirus to infect nondividing cells compared to other retroviruses because of its unique route of viral transfection by expressing both integrase [95] and Vpx proteins which interact with components of the nuclear pore complex $[96,97]$. Another advantage of lentivirus is the low prevalence of HIV infections, which lead relatively rare pre-existing immune conditions [98]. Thus, recombined Lentivirus vectors (LVs) could be designed as efficient vectors for transduction of both mature and immature DCs. Recent studies have demonstrated that, in comparison with lipofection, electroporation and AAV, LV is the most effective vector for transduction of BMDCs [99]. Many studies reported that the highly efficient transduction of DCs in vivo [100-102] and ex vivo [103] is possible by using LVs, this can be also used for shRNA transduction [104, 105]. Moreover, LVs can also be used to transfect monocytes before differentiating 
TABLE 1: Overview of recent studies using Ad vectors for gene transfer in DCs.

\begin{tabular}{|c|c|c|c|c|}
\hline Cancer & Transfer molecule & In vitro & In vivo in animal model & Reference \\
\hline \multirow{2}{*}{ Prostate } & tPSMA and $4-1 \mathrm{BBL}$ & High IFN-production & Strong antitumor immunity & {$[83]$} \\
\hline & STEAP & High IFN-production & $\begin{array}{l}\text { Inhibition of tumor growth, vaccination } \\
\text { delaying the growth of pre-established } \\
\text { tumors }\end{array}$ & {$[84]$} \\
\hline \multirow{4}{*}{ Hepatoma } & mTERT & $\begin{array}{l}\text { High IFN-and IL-2 } \\
\text { production }\end{array}$ & Inhibition of the tumor growth & {$[85]$} \\
\hline & hTERT & $\begin{array}{l}\text { Inducing strong CTL } \\
\text { response }\end{array}$ & Inducing anti-tumour immunity & {$[63]$} \\
\hline & $\mathrm{HCC}$ and $\mathrm{CD} 40 \mathrm{~L}$ & Increasing DCs IL-12 & $\begin{array}{l}\text { Inducing complete regression of established } \\
\text { tumors and long-term immunity against } \\
\text { tumor recurrence }\end{array}$ & {$[86]$} \\
\hline & AFP and HBsAg & $\begin{array}{l}\text { Inducing CTLs killing } \\
\text { HepG2.2.15 cell lines }\end{array}$ & $\begin{array}{l}\text { Inhibition of tumor growth in } \\
\text { immunodeficiency mice }\end{array}$ & {$[87]$} \\
\hline \multirow[t]{2}{*}{ Leukemia } & Survivin and GM-CSF & $\begin{array}{l}\text { Much higher activity of } \\
\text { CTL than DCs with } \\
\text { either }\end{array}$ & No data available & {$[88]$} \\
\hline & IL-12 with tumor cell lysate & No data available & Prolonged survival time & [89] \\
\hline Metastatic lung cancer & IL-12- and 4-1BBL & $\begin{array}{l}\text { High IFN-production } \\
\text { and CTLs response }\end{array}$ & $\begin{array}{l}\text { Greater antitumor and antimetastatic effects } \\
\text { than either treatment alone higher } \\
\text { migratory abilities of DCs }\end{array}$ & {$[90]$} \\
\hline Lung & livin & $\begin{array}{l}\text { Inducing CTLs lysing } \\
\text { LLC }\end{array}$ & $\begin{array}{l}\text { Inducing a potent protective and } \\
\text { therapeutic antitumor immunity }\end{array}$ & [91] \\
\hline Urologic cancer cells & Survivin & $\begin{array}{l}\text { Inducing CTLs against } \\
\text { various bladder, kidney, } \\
\text { and prostate cancer cells }\end{array}$ & No data available & {$[92]$} \\
\hline
\end{tabular}

into DCs, which could bypass the preactivation agents such as granulocyte-macrophage colony-stimulating actor (GMCSF) and interleukin (IL)-4 [106]. Further modified work has been performed these years and may be extended to clinical trials. However, gene therapy using LVs has a possible risk of insertional mutagenesis.

3.2.2. DCs Transferred by Nonviral Carriers. Although viral vectors have been demonstrated to be more efficient in gene delivery, the clinical application is limited due to their risk in safety and unexpected adverse effects [107]. In contrast, nonviral vectors, such as various liposomes and polyion complexes, have been increasingly developed these years because of their low immune response and ease of synthesis under controllable conditions and ease to be modified. The major limitations are their inefficient transfer, low gene expression and relatively high cytotoxicity by nature. Here is the advanced development in several nonviral vectors.

Liposomes. Liposomes are artificial closed vesicles of lipid bilayer membranes. Liposomes, modified with specific targeting molecular structures on surface, can be used as transfection vectors for DCs. After the APCs interact with the targeting liposomes which contain antigen peptides or DNA, the APC-mediated CTL responses are effectively enhanced [108]. Different formulations of liposomes are designed to improve the uptake by DCs through different receptor-mediated routes. These formulations of liposomes include liposomes prepared with mannosylated phosphatidylethanolamine (Man-PE), trimethyl ammonium propane [2], and phosphatidylserine [109] corresponding to mannose receptor (MR), negatively charged surface proteins and PS receptor of DCs, respectively [110].

Over the last decade, several studies have demonstrated that MR-mediated gene transfer into macrophages and DCs using mannosylated cationic liposomes can elicit effective immune responses [111-113]. MR is a typical receptor of Ctype lectins, which are structurally related to surface-bound nonspecific pattern recognition receptors on the surface of monocytes, macrophages, and DCs. Using the affinity of MR with mannose-containing ligands, researchers prepared several mannosylated cationic liposomes to encapsulate DNA or RNA for gene delivery purpose. It was also reported that the transfection efficiency of macrophages and DCs was enhanced by a combination method using mannosylated lipoplexes and bubble liposomes (BLs) with ultrasound exposure. In the liver and spleen, the transfection efficiency by using this combination method was higher than that of naked pDNA or combination of unmodified lipoplexes and BLs [114]. Moreover, besides DNA delivery, siRNA silencing of DCs with liposomes is also widely used $[115,116]$.

Fusogenic liposome (FL) encapsulating DNA is a novel biological strategy to deliver antigen gene directly into the cytoplasm of DCs via membrane fusion. It has been demonstrated that FL-mediated OVA-gene delivery can induce potent presentation of antigen via the MHC class I-dependent pathway in vitro and then can induce a series 
of immune responses [117]. Complexes of lipoplexes with $\mathrm{pH}$-sensitive fusogenic liposomes can not only transfect various malignant cells, but also can transfect a murine DC line (DC2.4) [118]. These complexes exhibited higher transfection efficiency to DC2.4 cells than some other commercially available reagents. So these new complexes may be valuable for the transfection of DCs.

Complex Particles. Recently, complex particles such as cationic polymers have been used as promising vectors for DNA delivery, because of their electrostatic interactions and ease of modification in targeting ligands. The advantages of cationic polymers used as gene carriers include (1) compression of the DNA into complex particles with small size and high density, which makes gene easier to transfer into cells; (2) electrostatic attraction with the cell membrane to facilitate endocytosis; (3) stability under the electrostatic repulsion. Nowadays, chitosan and biodegradable microparticles such as poly (ethylene-imine) (PEI), and so forth, attracted considerable attention in this field.

Chitosan has been used as gene delivery carrier because of good biocompatibility and high positive charge density in recent years [119]. The transfection efficiency of chitosan depends on its molecular weight, DNA complexes charge ratio, $\mathrm{pH}$, and particle sizes as well as the type of cells $[120,121]$. To overcome the weakness of chitosan such as poor solubility, low rate of DNA release and low efficiency of transfection, hydrophilic, and hydrophobic structure modification have been carried out. Although unmodified chitosan may not be a good gene delivery carrier for DCs because of its low transfection efficiency, some modified chitosan showed better behavior in delivering genes into DCs. For example, to enhance the IL-12 gene delivery to DCs in vivo, mannosylated chitosan (MC), which is used to induce mannose receptor-mediated endocytosis, was prepared to encapsulate IL-12 gene into DCs. MC not only has good physicochemical properties and low cytotoxicity, but also shows much more enhanced transfection efficiency to DCs rather than unmodified chitosan in vitro. And tumor growth in mouse model was suppressed by intratumoral injection of MC/plasmid encoding murine IL-12 [122, 123]. Moreover, Zhou et al. [124] developed MC microspheres containing PEI/DNA complexes, and used this carrier to improve the delivery of DNA into DCs. After in vivo immunization, the microspheres induced significantly enhanced serum antibody and cytotoxic T-lymphocyte (CTL) responses. Therefore, MC-mediated cytokine gene delivery system on DCs may be a potential approach for cancer immunotherapy.

Biodegradable microparticles which are easily cleared by physiological clearance systems can avoid the possible cytotoxicity caused by accumulation in cells and tissues. Microparticles prepared from poly (lactide) [125], poly(lactide-coglycolide) (PLGA), poly (orthoesters) (POE), and other polymers microparticles have been well studied in recent years. Their biodegradability, biocompatibility, and low toxicity properties make them suitable carriers for DNA vaccines. The virus-associated risk of adverse effects can also be avoided because these microparticles do not incorporate into the host cell's nucleus. Several studies have demonstrated that immune responses are induced by particle-DNA vaccines. Recently, it was reported that PLGA/PEI-DNA complex nanospheres have been developed as an efficient delivery system for the DCs. And the efficiency can be significantly promoted by modifying with nuclear localization signal (NLS) [126]. Also, such material as POE with lower cytoxicity was used to encapsulate plasmids and it induced both cellular and humoral responses in vivo [127]. The internalization of the particles into DCs is through phagocytosis, and the microparticles are easily phagocytosed by DC in vitro or in vivo [128].

It is well known that PEI is the most effective nonviral carrier for gene delivery. It has relative high transfection capacity due to its characteristics such as its ease in combining with DNA, binding with the cell and escaping from the endosome. Nowadays, the hotspots of research gradually focused on reducing its toxicity by various modifications. It is mainly because, cytotoxicity increases as the molecular weight increases, while the efficiency of gene loading and transfection increases correspondingly. Recently, Ali and Mooney [129] demonstrated that it showed sustained and long-term presentation when DCs were transfected with the PEI condensed with gene encoding GM-CSF. And they also use polymer PLG as scaffold fabrication continuously stimulated DCs with both GM-CSF and PEI-DNA. This process led to a 20 -fold increase in gene expression than no scaffold groups, and 10 days expression in vitro. These results largely encouraged the development of biomaterials, such as PEI, coordinated with other macroporous scaffolds as a transfer system for DC-based vaccination. Besides, PEIbased nanoparticles could also be used to encapsulate siRNA to transfer DCs against tumor cells [130].

Transfection Systems for Nonviral Carriers Used in DCs Transfer. Although nonviral gene delivery system has many advantages as reported, it still cannot reach the high transfection efficiency as viral vectors do, and the period of transfection is also far from satisfactory. To improve the efficiency, one of the methods is optimizing the whole transfection system. For this purpose, the reverse and threedimensional (3D) transfection systems have been proposed.

Some earlier studies demonstrated that reverse transfection method was more effective in enhancing the level and duration of gene expression than that of the conventional method on some cell lines [133, 134]. This may be due to the fact that DNA complexes can more easily transfect cells if they are in the area nearer to cells. In addition, cells tend to adhere to the surface and bottom of culture dish. Thus, attaching the DNA-complexes to the bottom of culture dishes before adding cells could enhance and prolong gene expression. Moreover, continuous interaction between DNAcomplexes and cells would minimize the influence of serum in the transfection activity of DNA-complexes.

Several physical, chemical, and biochemical factors, can influence gene transfection efficiency. Increasing studies have reported that, when cells are cultured in 3D systems, the results of transfection in various cells such as 
TABLe 2: Genes used for modification of DCs.

\begin{tabular}{lll}
\hline Groups & Genes coding factors & Effects \\
\hline TAAs & Gp100, MART-1, PSA, CEA, MUC-1, p53, OVA, & $\begin{array}{l}\text { Lastingly expressing tumor antigens to induce the } \\
\text { adverse effects of T-cells special response } \\
\text { Cytokines }\end{array}$ \\
& $\begin{array}{l}\text { IL-2, IL-7, IL-12, IL-15, IL-18 [131, 132], IL-21, } \\
\text { IL-23, IFN, TNF- } \alpha\end{array}$ & $\begin{array}{l}\text { To enhance the activity of antigen-presenting function } \\
\text { of DCs }\end{array}$ \\
Chemokines & CCL21, CCL22, XCL1, CXCL9, CXCL19, CX3CL1 & $\begin{array}{l}\text { To guide lymphocytes to the lymph nodes } \\
\text { To have angiostatic activity }\end{array}$ \\
$\begin{array}{l}\text { Costimulatory and } \\
\text { adhesion molecules }\end{array}$ & CD40L, CD70, 4-1BBL, OX40L RANKL, CD54, & $\begin{array}{l}\text { To enhance APC's ability to generate antitumor } \\
\text { immune responses } \\
\text { To improve adhesion interaction between DCs and T } \\
\text { cells }\end{array}$ \\
\hline
\end{tabular}

MSCs [135, 136] and HEK293T [137] showed higher efficiency than results by using the conventional and reverse methods. And in 3D systems, cells also exhibited better morphology. The reasons may include (1) scaffolds provide larger surface area and space for the interaction between DNA-complexes and cells than that in two-dimensional (2D) systems. (2) DNA complexes can be fixed on the scaffolds and prevented from aggregation in 3D systems. (3) Signaling pathway can be influenced by 3D systems. Ali and Mooney [129] reported that nonviral vector PEI/pDNA was immobilized on a nonwoven fabric with reverse transfection method. The scaffold was treated with negative charges to facilitate the adsorption of cationic DNA/PEI complex. DCs were effectively transfected in this $3 \mathrm{D}$ system, and the level of gene expression was significantly higher than that of conventional transfection. It should be noted that, to date, the application of $3 \mathrm{D}$ or scaffold transfer system in transfection of DCs is still a new area. So the methods of cell seeding and the properties of the scaffold are still needed further exploration.

\section{Genes Employed in DCs Transfer}

The DCs transferred with various genes can steadily and effectively express the proteins when DCs are refused ex vivo. After being transferred with TAA genes, DCs could express multiple antigens and epitopes. These antigens can be cross presented to MHC. DCs transferred with cytokines genes could produce large amounts of interleukin. Different genes encoding TAAs, cytokines, or chemokines are utilized to engineer DCs to increase immunogenicity. Subsequently, DCs transferred with the genes encoding TAAs can present the encoded proteins to MHC molecules and then to mediate T-cell responses. When DCs were transferred with genes encoding cytokines such as IL-7 or IL-12, the efficacy of generating $\mathrm{T}$ cells and immune response can be increased. When DCs were transferred with the genes encoding chemokines, the chemotaxis of DCs to T cells can be enhanced. Although this approach has not been used in clinic, it would be a potential strategy for genetic engineering technology on DCs. The genes used to transfer DCs are listed in Table 2 .

\section{Effective Cancer Immunotherapy Induced by Gene-Transferred DCs}

In recent years, DC vaccines, especially DNA-based DC vaccines, have been the focus of attention in cancer immunotherapy. The main process is transferring DCs in vitro, and then implanting them ex vivo. Finally, the tumor-specific CTL response would be activated, and cancer cells would be suppressed. These adoptive immunotherapy approaches have been improved and have achieved partial success in the treatment of malignant melanoma [34], renal cell carcinoma [138], malignant lymphoma [139], and other malignant diseases $[109,140]$. Most of them were phase I/II clinical trials.

Although various tumor types were studied, melanoma, and prostate cancer are two predominant tumors treated by gene-modified DC vaccine [141]. The clinical studies for DC-based genetically modified vaccination include both viral and nonviral approaches. In viral vaccinations, recombinant AdVs were mainly used, but their application in clinic is limited by the biosafety concerns. In contrast, nonviral carriers are widely used in clinical trials because of their low toxicity. The major barrier of nonviral carriers is their low transfer efficiency compared with viral vectors. In addition to the gene delivery approach, the conformation of DCs and the route of administration are also considered to be the important issues. The formulation of DCs includes not only monocytederived DCs and BMDCs, but also immature and mature ones. The administration methods mainly include intradermal, intravenous, intranodal, and intratumoral delivery.

The above information suggests that DC-based vaccination against cancer is a promising approach with low adverse effects, but advanced efficacy studies need to be carried out. Despite this limitation, recombination DC vaccine would be considered as an encouraging tool to treat cancer.

\section{Conclusions and Future Perspective}

DC vaccines can kill the cancer cells with little damage to normal cells by inducing and enhancing patient's own tumor-specific immune response. The function of DCs could be to optimize genetic modification by various TAAs or 
immune-modulatory molecules. Therefore, the application of ex vivo DC-based vaccination for cancer immunotherapy has many advantages because of its tumor-specific stimulation. However, for clinical applications using DC vaccines, lots of problems need to be solved, such as the low affinity between tumor epitopes and MHC, the frequency of vaccine delivery and immune procedures, and the difficulty to evaluate vaccines effect. Until now, many researchers used gene carriers and transfection systems in the recombination of DCs for effective cancer immunotherapy. With the development of materials science, targeted cell biology and molecular cytology, and so forth, various strategies have been introduced to optimize both viral and nonviral vectors for gene delivery into DCs. In addition, there is a requirement for further investigation in the use of the reverse and 3D systems to improve the nonviral transfection efficiency. These efforts are expected to facilitate future clinical applications of genemodified DCs for cancer therapy.

\section{Acknowledgments}

This work was financially supported by National Natural Science Foundation of China (no. 30973648), Zhejiang Provincial Natural Science Foundation of China (no. R2090176) and China-Japan Scientific Cooperation Program (no. 81011140077) supported by both NSFC, China and JSPS, Japan. The authors thank Dr. Yu-Lan Hu (Institute of Pharmaceutics, Zhejiang University) for her critical review of the paper.

\section{References}

[1] A. Jemal, R. Siegel, E. Ward, Y. Hao, J. Xu, and M. J. Thun, "Cancer statistics, 2009," CA Cancer Journal for Clinicians, vol. 59, no. 4, pp. 225-249, 2009.

[2] T. Hinz, C. J. Buchholz, T. Van Der Stappen, K. Cichutek, and U. Kalinke, "Manufacturing and quality control of cell-based tumor vaccines: a scientific and a regulatory perspective," Journal of Immunotherapy, vol. 29, no. 5, pp. 472-476, 2006.

[3] C. Palena, S. I. Abrams, J. Schlom, and J. W. Hodge, "Cancer vaccines: preclinical studies and novel strategies," Advances in Cancer Research, vol. 95, pp. 115-145, 2006.

[4] D. Dudziak, A. O. Kamphorst, G. F. Heidkamp et al., "Differential antigen processing by dendritic cell subsets in vivo," Science, vol. 315, no. 5808, pp. 107-111, 2007.

[5] M. V. Dhodapkar, K. M. Dhodapkar, and A. K. Palucka, "Interactions of tumor cells with dendritic cells: balancing immunity and tolerance," Cell Death and Differentiation, vol. 15, no. 1, pp. 39-50, 2008.

[6] C. A. Janeway and R. Medzhitov, "Innate immune recognition," Annual Review of Immunology, vol. 20, pp. 197-216, 2002.

[7] A. A. Itano and M. K. Jenkins, "Antigen presentation to naive CD4 T cells in the lymph node," Nature Immunology, vol. 4, no. 8, pp. 733-739, 2003.

[8] G. J. Randolph, V. Angeli, and M. A. Swartz, "Dendriticcell trafficking to lymph nodes through lymphatic vessels," Nature Reviews Immunology, vol. 5, no. 8, pp. 617-628, 2005.
[9] K. Inaba, J. P. Metlay, M. T. Crowley, and R. M. Steinman, "Dendritic cells pulsed with protein antigens in vitro can prime antigen-specific, MHC-restricted T cells in situ," Journal of Experimental Medicine, vol. 172, no. 2, pp. 631640, 1990.

[10] S. Paczesny, H. Ueno, J. Fay, J. Banchereau, and A. K. Palucka, "Dendritic cells as vectors for immunotherapy of cancer," Seminars in Cancer Biology, vol. 13, no. 6, pp. 439-447, 2003.

[11] A. Rughetti, M. Biffoni, M. Sabbatucci et al., "Transfected human dendritic cells to induce antitumor immunity," Gene Therapy, vol. 7, no. 17, pp. 1458-1466, 2000.

[12] V. H. Engelhard, T. N. J. Bullock, T. A. Colella, S. L. Sheasley, and D. W. Mullins, "Antigens derived from melanocyte differentiation proteins: self-tolerance, autoimmunity, and use for cancer immunotherapy," Immunological Reviews, vol. 188, pp. 136-146, 2002.

[13] E. M. Shevach, "Fatal attraction: tumors beckon regulatory T cells," Nature Medicine, vol. 10, no. 9, pp. 900-901, 2004.

[14] X. Zhang, J. R. Gordon, and J. Xiang, "Advances in dendritic cell-based vaccine of cancer," Cancer Biotherapy and Radiopharmaceuticals, vol. 17, no. 6, pp. 601-619, 2002.

[15] F. Sallusto and A. Lanzavecchia, "Efficient presentation of soluble antigen by cultured human dendritic cells is maintained by granulocyte/macrophage colony-stimulating factor plus interleukin 4 and downregulated by tumor necrosis factor $\alpha$," Journal of Experimental Medicine, vol. 179, no. 4, pp. 11091118, 1994.

[16] J. A. Villadangos, W. R. Heath, and F. R. Carbone, “Outside looking in: the inner workings of the crosspresentation pathway within dendritic cells," Trends in Immunology, vol. 28, no. 2, pp. 45-47, 2007.

[17] K. Shortman and S. H. Naik, "Steady-state and inflammatory dendritic-cell development," Nature Reviews Immunology, vol. 7, no. 1, pp. 19-30, 2007.

[18] B. Dubois, J. M. Bridon, J. Fayette et al., "Dendritic cells directly modulate B cell growth and differentiation," Journal of Leukocyte Biology, vol. 66, no. 2, pp. 224-230, 1999.

[19] K. Shortman and Y. J. Liu, "Mouse and human dendritic cell subtypes," Nature Reviews Immunology, vol. 2, no. 3, pp. 151$161,2002$.

[20] M. Merad and M. G. Manz, "Dendritic cell homeostasis," Blood, vol. 113, no. 15, pp. 3418-3427, 2009.

[21] R. Maldonado-López, T. De Smedt, B. Pajak et al., "Role of CD $8 \alpha$ and CD $8 \alpha$ dendritic cells in the induction of primary immune responses in vivo," Journal of Leukocyte Biology, vol. 66, no. 2, pp. 242-246, 1999.

[22] B. Pulendran, J. L. Smith, G. Caspary et al., "Distinct dendritic cell subsets differentially regulate the class of immune response in vivo," Proceedings of the National Academy of Sciences of the United States of America, vol. 96, no. 3, pp. 1036-1041, 1999.

[23] N. S. Wilson and J. A. Villadangos, "Regulation of antigen presentation and cross-presentation in the dendritic cell network: facts, hypothesis, and immunological implications," Advances in Immunology, vol. 86, pp. 241-305, 2005.

[24] C. Reis e Sousa, "Dendritic cells in a mature age," Nature Reviews Immunology, vol. 6, no. 6, pp. 476-483, 2006.

[25] J. A. Villadangos and W. R. Heath, "Life cycle, migration and antigen presenting functions of spleen and lymph node dendritic cells: limitations of the Langerhans cells paradigm," Seminars in Immunology, vol. 17, no. 4, pp. 262-272, 2005. 
[26] S. Akira and K. Takeda, "Toll-like receptor signalling," Nature Reviews Immunology, vol. 4, no. 7, pp. 499-511, 2004.

[27] H. Kondo, S. Hazama, T. Kawaoka et al., "Adoptive immunotherapy for pancreatic cancer using MUC1 peptidepulsed dendritic cells and activated T lymphocytes," Anticancer Research, vol. 28, no. 1, pp. 379-387, 2008.

[28] E. Meylan, J. Tschopp, and M. Karin, "Intracellular pattern recognition receptors in the host response," Nature, vol. 442, no. 7098, pp. 39-44, 2006.

[29] P. Salgame, J. S. Abrams, C. Clayberger et al., "Differing lymphokine profiles of functional subsets of human CD4 and CD8 T cell clones," Science, vol. 254, no. 5029, pp. 279-282, 1991.

[30] C. Caux, C. Massacrier, B. Vanbervliet et al., "Activation of human dendritic cells through CD40 cross-linking," Journal of Experimental Medicine, vol. 180, no. 4, pp. 1263-1272, 1994.

[31] A. Macagno, G. Napolitani, A. Lanzavecchia, and F. Sallusto, "Duration, combination and timing: the signal integration model of dendritic cell activation," Trends in Immunology, vol. 28, no. 5, pp. 227-233, 2007.

[32] S. P. Schoenberger, R. E. M. Toes, E. I. H. Van Dervoort, R. Offringa, and C. J. M. Melief, "T-cell help for cytotoxic T lymphocytes is mediated by CD40-CD4OL interactions," Nature, vol. 393, no. 6684, pp. 480-483, 1998.

[33] P. Pierre, S. J. Turley, E. Gatti et al., "Developmental regulation of MHC class II transport in mouse dendritic cells," Nature, vol. 388, no. 6644, pp. 787-792, 1997.

[34] L. Engell-Noerregaard, T. H. Hansen, M. H. Andersen, P. Thor Straten, and I. M. Svane, "Review of clinical studies on dendritic cell-based vaccination of patients with malignant melanoma: assessment of correlation between clinical response and vaccine parameters," Cancer Immunology, Immunotherapy, vol. 58, no. 1, pp. 1-14, 2009.

[35] E. Gilboa, "DC-based cancer vaccines," Journal of Clinical Investigation, vol. 117, no. 5, pp. 1195-1203, 2007.

[36] S. M. Kaech and R. Ahmed, "Immunology: CD8 T cells remember with a little help," Science, vol. 300, no. 5617, pp. 263-265, 2003.

[37] K. Kawamura, N. Kadowaki, R. Suzuki et al., "Dendritic cells that endocytosed antigen-containing IgG-liposomes elicit effective antitumor immunity," Journal of Immunotherapy, vol. 29, no. 2, pp. 165-174, 2006.

[38] E. S. Trombetta and I. Mellman, "Cell biology of antigen processing in vitro and in vivo," Annual Review of Immunology, vol. 23, pp. 975-1028, 2005.

[39] W. R. Heath, G. T. Belz, G. M. N. Behrens et al., "Crosspresentation, dendritic cell subsets, and the generation of immunity to cellular antigens," Immunological Reviews, vol. 199, pp. 9-26, 2004.

[40] A. F. Ochsenbein, S. Sierro, B. Odermatt et al., "Roles of tumour localization, second signals and cross priming in cytotoxic T-cell induction," Nature, vol. 411, no. 6841, pp. 1058-1064, 2001.

[41] G. Willimsky and T. Blankenstein, "Sporadic immunogenic tumours avoid destruction by inducing T-cell tolerance," Nature, vol. 437, no. 7055, pp. 141-146, 2005.

[42] S. Raychaudhuri and K. L. Rock, "Fully mobilizing host defense: building better vaccines," Nature Biotechnology, vol. 16, no. 11, pp. 1025-1033, 1998.

[43] D. S. Bangari and S. K. Mittal, "Current strategies and future directions for eluding adenoviral vector immunity," Current Gene Therapy, vol. 6, no. 2, pp. 215-226, 2006.
[44] A. Tuettenberg, C. Becker, E. Huter, J. Knop, A. H. Enk, and H. Jonuleit, "Induction of strong and persistent MelanA/MART-1-specific immune responses by adjuvant dendritic cell-based vaccination of stage II melanoma patients," International Journal of Cancer, vol. 118, no. 10, pp. 2617-2627, 2006.

[45] J. Babatz, C. Röllig, B. Löbel et al., "Induction of cellular immune responses against carcinoembryonic antigen in patients with metastatic tumors after vaccination with altered peptide ligand-loaded dendritic cells," Cancer Immunology, Immunotherapy, vol. 55, no. 3, pp. 268-276, 2006.

[46] M. Y. Bae, N. H. Cho, and S. Y. Seong, "Protective antitumour immune responses by murine dendritic cells pulsed with recombinant Tat-carcinoembryonic antigen derived from Escherichia coli," Clinical and Experimental Immunology, vol. 157, no. 1, pp. 128-138, 2009.

[47] D. K. Kim, T. V. Lee, A. Castilleja et al., "Folate binding protein peptide 191-199 presented on dendritic cells can stimulate CTL from ovarian and breast cancer patients," Anticancer Research, vol. 19, no. 4, pp. 2907-2916, 1999.

[48] D. K. Kim, J. H. Kim, Y. T. Kim, J. W. Kim, and C. G. Ioannides, "The comparoison of cytotoxic T-lymphocyte effects of dendritic cells stimulated by the folate binding protein peptide cultured with IL-15 and IL-2 in solid tumor," Yonsei Medical Journal, vol. 43, no. 6, pp. 691-700, 2002.

[49] S. Garetto, F. Sizzano, D. Brusa, A. Tizzani, F. Malavasi, and L. Matera, "Binding of prostate-specific membrane antigen to dendritic cells: a critical step in vaccine preparation," Cytotherapy, vol. 11, no. 8, pp. 1090-1100, 2009.

[50] Y. Waeckerle-Men, E. Uetz-Von Allmen, M. Fopp et al., "Dendritic cell-based multi-epitope immunotherapy of hormone-refractory prostate carcinoma," Cancer Immunology, Immunotherapy, vol. 55, no. 12, pp. 1524-1533, 2006.

[51] H. Yang, N. H. Cho, and S. Y. Seong, "The Tat-conjugated $\mathrm{N}$-terminal region of mucin antigen 1 (MUC1) induces protective immunity against MUC1-expressing tumours," Clinical and Experimental Immunology, vol. 158, no. 2, pp. 174-185, 2009.

[52] J. Wierecky, M. Mueller, and P. Brossart, "Dendritic cellbased cancer immunotherapy targeting MUC-1," Cancer Immunology, Immunotherapy, vol. 55, no. 1, pp. 63-67, 2006.

[53] S. J. Woo, C. H. Kim, M. Y. Park et al., "Co-administration of carcinoembryonic antigen and HIV TAT fusion protein with CpG-oligodeoxynucleotide induces potent antitumor immunity," Cancer Science, vol. 99, no. 5, pp. 1034-1039, 2008.

[54] L. Fong and E. G. Engleman, "Dendritic cells in cancer immunotherapy," Annual Review of Immunology, vol. 18, pp. 245-273, 2000.

[55] M. Schott, J. Feldkamp, D. Schattenberg et al., "Induction of cellular immunity in a parathyroid carcinoma treated with tumor lysate-pulsed dendritic cells," European Journal of Endocrinology, vol. 142, no. 3, pp. 300-306, 2000.

[56] M. Schnurr, P. Galambos, C. Scholz et al., "Tumor cell lysate-pulsed human dendritic cells induce a T-cell response against pancreatic carcinoma cells: an in vitro model for the assessment of tumor vaccines," Cancer Research, vol. 61, no. 17, pp. 6445-6450, 2001.

[57] X. Zhao, Y. Q. Wei, and Z. L. Peng, "Induction of T cell responses against autologous ovarian tumors with whole tumor cell lysate-pulsed dendritic cells," Immunological Investigations, vol. 30, no. 1, pp. 33-45, 2001. 
[58] N. Inzkirweli, B. Gückel, C. Sohn, D. Wallwiener, G. Bastert, and M. Lindner, "Antigen loading of dendritic cells with apoptotic tumor cell-preparations is superior to that using necrotic cells or tumor lysates," Anticancer Research, vol. 27, no. 4, pp. 2121-2129, 2007.

[59] D. Boczkowski, S. K. Nair, D. Snyder, and E. Gilboa, "Dendritic cells pulsed with RNA are potent antigen-presenting cells in vitro and in vivo," Journal of Experimental Medicine, vol. 184, no. 2, pp. 465-472, 1996.

[60] D. M. Ashley, B. Faiola, S. Nair, L. P. Hale, D. D. Bigner, and E. Gilboa, "Bone marrow-generated dendritic cells pulsed with tumor extracts or tumor RNA induce antitumor immunity against central nervous system tumors," Journal of Experimental Medicine, vol. 186, no. 7, pp. 1177-1182, 1997.

[61] R. K. Tyagi, S. Mangal, N. Garg, and P. K. Sharma, "RNA-based immunotherapy of cancer: role and therapeutic implications of dendritic cells," Expert Review of Anticancer Therapy, vol. 9, no. 1, pp. 97-114, 2009.

[62] J. J. Hernando, T. W. Park, H. P. Fischer et al., "Vaccination with dendritic cells transfected with mRNA-encoded folatereceptor- $\alpha$ for relapsed metastatic ovarian cancer," Lancet Oncology, vol. 8, no. 5, pp. 451-454, 2007.

[63] L. Chen, X. D. Tang, S. T. Yu et al., "Induction of antitumour immunity by dendritic cells transduced with hTERT recombinant adenovirus in mice," Journal of Pathology, vol. 217, no. 5, pp. 685-692, 2009.

[64] C. H. Kim, J. S. Yoon, H. J. Sohn et al., "Direct vaccination with pseudotype baculovirus expressing murine telomerase induces anti-tumor immunity comparable with RNA-electroporated dendritic cells in a murine glioma model," Cancer Letters, vol. 250, no. 2, pp. 276-283, 2007.

[65] D. Weissman, H. Ni, D. Scales et al., "HIV gag mRNA transfection of dendritic cells (DC) delivers encoded antigen to MHC class I and II molecules, causes DC maturation, and induces a potent human in vitro primary immune response," Journal of Immunology, vol. 165, no. 8, pp. 4710-4717, 2000.

[66] C. A. Nicolette, D. Healey, I. Tcherepanova et al., "Dendritic cells for active immunotherapy: optimizing design and manufacture in order to develop commercially and clinically viable products," Vaccine, vol. 25, no. 2, pp. B47-B60, 2007.

[67] D. Boczkowski and S. Nair, "RNA as performance-enhancers for dendritic cells," Expert Opinion on Biological Therapy, vol. 10, no. 4, pp. 563-574, 2010.

[68] M. A. Morse and H. K. Lyerly, "DNA and RNA modified dendritic cell vaccines," World Journal of Surgery, vol. 26, no. 7, pp. 819-825, 2002.

[69] V. F. I. Van Tendeloo, P. Ponsaerts, F. Lardon et al., "Highly efficient gene delivery by mRNA electroporation in human hematopoietic cells: superiority to lipofection and passive pulsing of mRNA and to electroporation of plasmid cDNA for tumor antigen loading of dendritic cells," Blood, vol. 98, no. 1, pp. 49-56, 2001.

[70] A. Ribas, "Genetically modified dendritic cells for cancer immunotherapy," Current Gene Therapy, vol. 5, no. 6, pp. 619-628, 2005.

[71] C. A. Mack, W. R. Song, H. Carpenter et al., "Circumvention of anti-adenovirus neutralizing immunity by administration of an adenoviral vector of an alternate serotype," Human Gene Therapy, vol. 8, no. 1, pp. 99-109, 1997.

[72] T. L. Wu and H. C. J. Ertl, "Immune barriers to successful gene therapy," Trends in Molecular Medicine, vol. 15, no. 1, pp. 32-39, 2009.
[73] N. Okada, T. Saito, Y. Masunaga et al., "Efficient antigen gene transduction using Arg-Gly-Asp fiber-mutant adenovirus vectors can potentiate antitumor vaccine efficacy and maturation of murine dendritic cells," Cancer Research, vol. 61, no. 21, pp. 7913-7919, 2001.

[74] H. Mizuguchi and T. Hayakawa, "Targeted adenovirus vectors," Human Gene Therapy, vol. 15, no. 11, pp. 1034-1044, 2004.

[75] Y. Eto, Y. Yoshioka, Y. Mukai, N. Okada, and S. Nakagawa, "Development of PEGylated adenovirus vector with targeting ligand," International Journal of Pharmaceutics, vol. 354, no. 1-2, pp. 3-8, 2008.

[76] X. Yao, Y. Yoshioka, T. Morishige et al., "Systemic administration of a PEGylated adenovirus vector with a cancer-specific promoter is effective in a mouse model of metastasis," Gene Therapy, vol. 16, no. 12, pp. 1395-1404, 2009.

[77] M. L. Edelstein, M. R. Abedi, J. Wixon, and R. M. Edelstein, "Gene therapy clinical trials worldwide 1989-2004-an overview," Journal of Gene Medicine, vol. 6, no. 6, pp. 597602, 2004.

[78] W. C. Adams, E. Bond, M. J. E. Havenga et al., "Adenovirus serotype 5 infects human dendritic cells via a coxsackievirusadenovirus receptor-independent receptor pathway mediated by lactoferrin and DC-SIGN," Journal of General Virology, vol. 90, no. 7, pp. 1600-1610, 2009.

[79] N. Okada, S. Iiyama, Y. Okada et al., "Immunological properties and vaccine efficacy of murine dendritic cells simultaneously expressing melanoma-associated antigen and interleukin-12," Cancer Gene Therapy, vol. 12, no. 1, pp. 7283, 2005.

[80] N. Okada, N. Mori, R. Koretomo et al., "Augmentation of the migratory ability of DC-based vaccine into regional lymph nodes by efficient CCR7 gene transduction," Gene Therapy, vol. 12, no. 2, pp. 129-139, 2005.

[81] A. Lundqvist, A. Choudhury, T. Nagata et al., "Recombinant adenovirus vector activates and protects human monocytederived dendritic cells from apoptosis," Human Gene Therapy, vol. 13, no. 13, pp. 1541-1549, 2002.

[82] L. Schumacher, A. Ribas, V. B. Dissette et al., "Human dendritic cell maturation by adenovirus transduction enhances tumor antigen-specific T-cell responses," Journal of Immunotherapy, vol. 27, no. 3, pp. 191-200, 2004.

[83] K. Youlin, W. Xiaodong, L. Xiuheng et al., "Anti-tumor immune response induced by dendritic cells transduced with truncated PSMA IRES 4-1BBL recombinant adenoviruses," Cancer Letters, vol. 293, no. 2, pp. 254-262, 2010.

[84] S. Kim, J. B. Lee, K. L. Geon, and J. Chang, "Vaccination with recombinant adenoviruses and dendritic cells expressing prostate-specific antigens is effective in eliciting CTL and suppresses tumor growth in the experimental prostate cancer," Prostate, vol. 69, no. 9, pp. 938-948, 2009.

[85] N. Jiang, G. S. Wang, H. Li et al., "Immunization with dendritic cells infected with mTERT adenovirus vector effectively elicits immunity against mouse $\mathrm{H} 22$ hepatoma in vivo," Zhonghua Zhong Liu Za Zhi, vol. 31, no. 6, pp. 405-409, 2009.

[86] M. A. Gonzalez-Carmona, V. Lukacs-Kornek, A. Timmerman et al., "CD40Ligand-expressing dendritic cells induce regression of hepatocellular carcinoma by activating innate and acquired immunity in vivo," Hepatology, vol. 48, no. 1, pp. 157-168, 2008. 
[87] J. Y. Yang, D. Y. Cao, Y. Xue, Z. C. Yu, and W. C. Liu, "Improvement of dendritic-based vaccine efficacy against hepatitis B virus-related hepatocellular carcinoma by two tumor-associated antigen gene-infected dendritic cells," Human Immunology, vol. 71, no. 3, pp. 255-262, 2010.

[88] X. P. Zhu, Z. Z. Chen, C. T. Li et al., "In vitro inducing effect of dendritic cells cotransfected with survivin and granulocyte-macrophage colony-stimulating factor on cytotoxic T cell to kill leukemic cells," Chinese Medical Journal, vol. 121, no. 21, pp. 2180-2184, 2008.

[89] B. Y. Tsai, Y. L. Lin, and B. L. Chiang, "Application of interleukin-12 expressing dendritic cells for the treatment of animal model of leukemia," Experimental Biology and Medicine, vol. 234, no. 8, pp. 952-960, 2009.

[90] J. H. Huang, S. N. Zhang, K. J. Choi et al., “Therapeutic and tumor-specific immunity induced by combination of dendritic cells and oncolytic adenovirus expressing IL-12 and 4-1BBL," Molecular Therapy, vol. 18, no. 2, pp. 264-274, 2010.

[91] J. Xie, L. Xiong, X. Tao et al., "Antitumor effects of murine bone marrow-derived dendritic cells infected with xenogeneic livin $\alpha$ recombinant adenoviral vectors against Lewis lung carcinoma," Lung Cancer, vol. 68, no. 3, pp. 338345, 2010.

[92] K. Kikkawa, R. Fujii, T. Kuramoto et al., "Dendritic cells with transduced survivin gene induce specific cytotoxic $\mathrm{T}$ lymphocytes in human urologic cancer cell lines," Urology, vol. 74, no. 1, pp. 222-228, 2009.

[93] C. Bello-Fernandez, M. Matyash, H. Strobl et al., "Efficient retrovirus-mediated gene transfer of dendritic cells generated from CD34+ cord blood cells under serum-free conditions," Human Gene Therapy, vol. 8, no. 14, pp. 1651-1658, 1997.

[94] P. Szabolcs, H. F. Gallardo, D. H. Ciocon, M. Sadelain, and J. W. Young, "Retrovirally transduced human dendritic cells express a normal phenotype and potent T-cell stimulatory capacity," Blood, vol. 90, no. 6, pp. 2160-2167, 1997.

[95] F. D. Bushman, "Integration site selection by lentiviruses: biology and possible control," Current Topics in Microbiology and Immunology, vol. 261, pp. 165-177, 2002.

[96] C. Goujon, L. Jarrosson-Wuillème, J. Bernaud, D. Rigal, J. L. Darlix, and A. Cimarelli, "With a little help from a friend: increasing HIV transduction of monocyte-derived dendritic cells with virion-like particles of SIV," Gene Therapy, vol. 13, no. 12, pp. 991-994, 2006.

[97] C. Goujon, L. Rivière, L. Jarrosson-Wuilleme et al., "SIV/HIV-2 Vpx proteins promote retroviral escape from a proteasome-dependent restriction pathway present in human dendritic cells," Retrovirology, vol. 4, article 2, 2007.

[98] C. Esslinger, P. Romero, and H. R. Macdonald, "Efficient transduction of dendritic cells and induction of a T-cell response by third-generation lentivectors," Human Gene Therapy, vol. 13, no. 9, pp. 1091-1100, 2002.

[99] G. B. Li and G. X. Lu, "Gene delivery efficiency in bone marrow-derived dendritic cells: comparison of four methods and optimization for lentivirus transduction," Molecular Biotechnology, vol. 43, no. 3, pp. 250-256, 2009.

[100] S. Han and L. J. Chang, "Immunity of lentiviral vectormodified dendritic cells," Methods in Molecular Biology, vol. 542, pp. 245-259, 2009.

[101] L. Yang, H. Yang, K. Rideout et al., "Engineered lentivector targeting of dendritic cells for in vivo immunization," Nature Biotechnology, vol. 26, no. 3, pp. 326-334, 2008.
[102] K. Breckpot, P. Emeagi, M. Dullaers, A. Michiels, C. Heirman, and K. Thielemans, "Activation of immature monocyte-derived dendritic cells after transduction with high doses of lentiviral vectors," Human Gene Therapy, vol. 18 , no. 6, pp. 536-546, 2007.

[103] R. Stripecke, "Lentiviral vector-mediated genetic programming of mouse and human dendritic cells," Methods in Molecular Biology, vol. 506, pp. 139-158, 2009.

[104] L. Zhang, M. Procuik, T. Fang, and S. K. P. Kung, "Functional analysis of the quantitative expression of a costimulatory molecule on dendritic cells using lentiviral vector-mediated RNA interference," Journal of Immunological Methods, vol. 344, no. 2, pp. 87-97, 2009.

[105] Y. Zhang, H. Yang, B. Xiao et al., "Dendritic cells transduced with lentiviral-mediated RelB-specific ShRNAs inhibit the development of experimental autoimmune myasthenia gravis," Molecular Immunology, vol. 46, no. 4, pp. 657-667, 2009.

[106] P. Veron, S. Boutin, J. Bernard, O. Danos, J. Davoust, and C. Masurier, "Efficient transduction of monocyte- and CD34+derived Langerhans cells with lentiviral vectors in the absence of phenotypic and functional maturation," Journal of Gene Medicine, vol. 8, no. 8, pp. 951-961, 2006.

[107] S. Hacein-Bey-Abina, C. Von Kalle, M. Schmidt et al., "A serious adverse event after successful gene therapy for X-linked severe combined immunodeficiency," The New England Journal of Medicine, vol. 348, no. 3, pp. 255-256, 2003.

[108] J. Ren, J. Jia, H. Zhang et al., "Dendritic cells pulsed with $\alpha$-fetoprotein and mutant P53 fused gene induce bi-targeted cytotoxic T lymphocyte response against hepatic carcinoma," Cancer Science, vol. 99, no. 7, pp. 1420-1426, 2008.

[109] S. J. Antonia, N. Mirza, I. Fricke et al., "Combination of p53 cancer vaccine with chemotherapy in patients with extensive stage small cell lung cancer," Clinical Cancer Research, vol. 12, no. 3, pp. 878-887, 2006.

[110] C. Foged, C. Arigita, A. Sundblad, W. Jiskoot, G. Storm, and S. Frokjaer, "Interaction of dendritic cells with antigencontaining liposomes: effect of bilayer composition," Vaccine, vol. 22, no. 15-16, pp. 1903-1913, 2004.

[111] M. Yamada, M. Nishikawa, S. Kawakami et al., "Tissue and intrahepatic distribution and subcellular localization of a mannosylated lipoplex after intravenous administration in mice," Journal of Controlled Release, vol. 98, no. 1, pp. 157167, 2004.

[112] Y. Lu, S. Kawakami, F. Yamashita, and M. Hashida, "Development of an antigen-presenting cell-targeted DNA vaccine against melanoma by mannosylated liposomes," Biomaterials, vol. 28, no. 21, pp. 3255-3262, 2007.

[113] Y. Hattori, S. Kawakami, K. Nakamura, F. Yamashita, and M. Hashida, "Efficient gene transfer into macrophages and dendritic cells by in vivo gene delivery with mannosylated lipoplex via the intraperitoneal route," Journal of Pharmacology and Experimental Therapeutics, vol. 318, no. 2, pp. 828834, 2006.

[114] R. Suzuki, Y. Oda, N. Utoguchi et al., "A novel strategy utilizing ultrasound for antigen delivery in dendritic cellbased cancer immunotherapy," Journal of Controlled Release, vol. 133, no. 3, pp. 198-205, 2009.

[115] X. Zheng, C. Vladau, X. Zhang et al., "A novel in vivo siRNA delivery system specifically targeting dendritic cells and silencing CD40 genes for immunomodulation," Blood, vol. 113, no. 12, pp. 2646-2654, 2009. 
[116] A. Orlacchio, S. Martino, I. Di Girolamo, R. Tiribuzi, F. D'Angelo, and A. Datti, "Efficient siRNA delivery by the cationic liposome DOTAP in human hematopoietic stem cells differentiating into dendritic cells," Journal of Biomedicine and Biotechnology, vol. 2009, Article ID 410260, 2009.

[117] T. Yoshikawa, S. Imazu, J. Q. Gao et al., "Augmentation of antigen-specific immune responses using DNA-fusogenic liposome vaccine," Biochemical and Biophysical Research Communications, vol. 325, no. 2, pp. 500-505, 2004.

[118] E. Yuba, C. Kojima, N. Sakaguchi, A. Harada, K. Koiwai, and K. Kono, "Gene delivery to dendritic cells mediated by complexes of lipoplexes and $\mathrm{pH}$-sensitive fusogenic polymermodified liposomes," Journal of Controlled Release, vol. 130, no. 1, pp. 77-83, 2008.

[119] W. Weecharangsan, P. Opanasopit, T. Ngawhirunpat et al., "Evaluation of chitosan salts as non-viral gene vectors in CHO-K1 cells," International Journal of Pharmaceutics, vol. 348, no. 1-2, pp. 161-168, 2008.

[120] M. Lavertu, S. Méthot, N. Tran-Khanh, and M. D. Buschmann, "High efficiency gene transfer using chitosan/DNA nanoparticles with specific combinations of molecular weight and degree of deacetylation," Biomaterials, vol. 27, no. 27, pp. 4815-4824, 2006.

[121] T. Dastan and K. Turan, "In vitro characterization and delivery of chitosan-DNA microparticles into mammalian cells," Journal of Pharmacy and Pharmaceutical Sciences, vol. 7, no. 2, pp. 205-214, 2004.

[122] T. H. Kim, J. W. Nah, M. H. Cho, T. G. Park, and N. S. Cho, "Receptor-mediated gene delivery into antigen presenting cells using mannosylated chitosan/DNA nanoparticles," Journal of Nanoscience and Nanotechnology, vol. 6, no. 9-10, pp. 2796-2803, 2006.

[123] T. H. Kim, H. Jin, H. W. Kim, M. H. Cho, and C. S. Cho, "Mannosylated chitosan nanoparticle-based cytokine gene therapy suppressed cancer growth in BALB/c mice bearing CT-26 carcinoma cells," Molecular Cancer Therapeutics, vol. 5, no. 7, pp. 1723-1732, 2006.

[124] X. Zhou, B. Liu, X. Yu et al., "Controlled release of PEI/DNA complexes from mannose-bearing chitosan microspheres as a potent delivery system to enhance immune response to HBV DNA vaccine," Journal of Controlled Release, vol. 121, no. 3, pp. 200-207, 2007.

[125] S. C. Ng, S. Plamondon, M. A. Kamm et al., "Immunosuppressive effects via human intestinal dendritic cells of probiotic bacteria and steroids in the treatment of acute ulcerative colitis," Inflammatory Bowel Diseases, vol. 16, no. 8, pp. 1286-1298, 2010.

[126] T. Kanazawa, Y. Takashima, M. Murakoshi, Y. Nakai, and H. Okada, "Enhancement of gene transfection into human dendritic cells using cationic PLGA nanospheres with a synthesized nuclear localization signal," International Journal of Pharmaceutics, vol. 379, no. 1-2, pp. 187-195, 2009.

[127] C. Wang, Q. Ge, D. Ting et al., "Molecularly engineered poly(ortho ester) microspheres for enhanced delivery of DNA vaccines," Nature Materials, vol. 3, no. 3, pp. 190-196, 2004.

[128] L. Thiele, H. P. Merkle, and E. Walter, "Phagocytosis and phagosomal fate of surface-modified microparticles in dendritic cells and macrophages," Pharmaceutical Research, vol. 20, no. 2, pp. 221-228, 2003.
[129] O. A. Ali and D. J. Mooney, "Sustained GM-CSF and PEI condensed pDNA presentation increases the level and duration of gene expression in dendritic cells," Journal of Controlled Release, vol. 132, no. 3, pp. 273-278, 2008.

[130] J. R. Cubillos-Ruiz, X. Engle, U. K. Scarlett et al., "Polyethylenimine-based siRNA nanocomplexes reprogram tumor-associated dendritic cells via TLR5 to elicit therapeutic antitumor immunity," Journal of Clinical Investigation, vol. 119, no. 8, pp. 2231-2244, 2009.

[131] L. Vujanovic, E. Ranieri, A. Gambotto, W. C. Olson, J. M. Kirkwood, and W. J. Storkus, "IL-12p70 and IL-18 genemodified dendritic cells loaded with tumor antigen-derived peptides or recombinant protein effectively stimulate specific Type-1 CD4+ T-cell responses from normal donors and melanoma patients in vitro," Cancer Gene Therapy, vol. 13, no. 8, pp. 798-805, 2006.

[132] X. M. Tong, S. E. Zheng, A. Bader et al., "Construction of expression vector of HTERT- HIL18 fusion gene and induction of cytotoxic T lymphocyte response against hTERT," European Journal of Medical Research, vol. 13, no. 1, pp. 714, 2008.

[133] O. Mannherz, D. Mertens, M. Hahn, and P. Lichter, "Functional screening for proapoptotic genes by reverse transfection cell array technology," Genomics, vol. 87, no. 5, pp. 665-672, 2006.

[134] A. Okazaki, J. I. Jo, and Y. Tabata, "A reverse transfection technology to genetically engineer adult stem cells," Tissue Engineering, vol. 13, no. 2, pp. 245-251, 2007.

[135] C. Holladay, M. Keeney, U. Greiser, M. Murphy, T. O’Brien, and A. Pandit, "A matrix reservoir for improved control of non-viral gene delivery," Journal of Controlled Release, vol. 136, no. 3, pp. 220-225, 2009.

[136] Y. Lei and T. Segura, "DNA delivery from matrix metalloproteinase degradable poly(ethylene glycol) hydrogels to mouse cloned mesenchymal stem cells," Biomaterials, vol. 30, no. 2, pp. 254-265, 2009.

[137] J. H. Jang, Z. Bengali, T. L. Houchin, and L. D. Shea, "Surface adsorption of DNA to tissue engineering scaffolds for efficient gene delivery," Journal of Biomedical Materials Research A, vol. 77, no. 1, pp. 50-58, 2006.

[138] B. Frankenberger, S. Regn, C. Geiger et al., "Cell-based vaccines for renal cell carcinoma: genetically-engineered tumor cells and monocyte-derived dendritic cells," World Journal of Urology, vol. 23, no. 3, pp. 166-174, 2005.

[139] X. P. Zhu, Z. Z. Chen, J. D. Hu, C. T. Li, T. Yang, and Z. $\mathrm{S}$. Xu, "Induction of anti-lymphoma cytotoxic $\mathrm{T}$ cell effect by dendritic cells transfected with recombinant adenovirus vectors carrying survivin gene," Zhongguo Shi Yan Xue Ye Xue Za Zhi, vol. 15, no. 3, pp. 591-593, 2007.

[140] W. Xiong, M. Candolfi, C. Liu et al., "Human Flt3L generates dendritic cells from canine peripheral blood precursors: implications for a dog glioma clinical trial," PLoS One, vol. 5, no. 6, Article ID e11074, 2010.

[141] E. L. Smits, S. Anguille, N. Cools, Z. N. Berneman, and V. F. Van Tendeloo, "Dendritic cell-based cancer gene therapy," Human Gene Therapy, vol. 20, no. 10, pp. 1106-1118, 2009. 


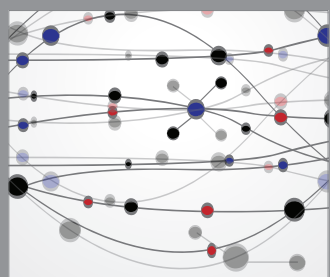

The Scientific World Journal
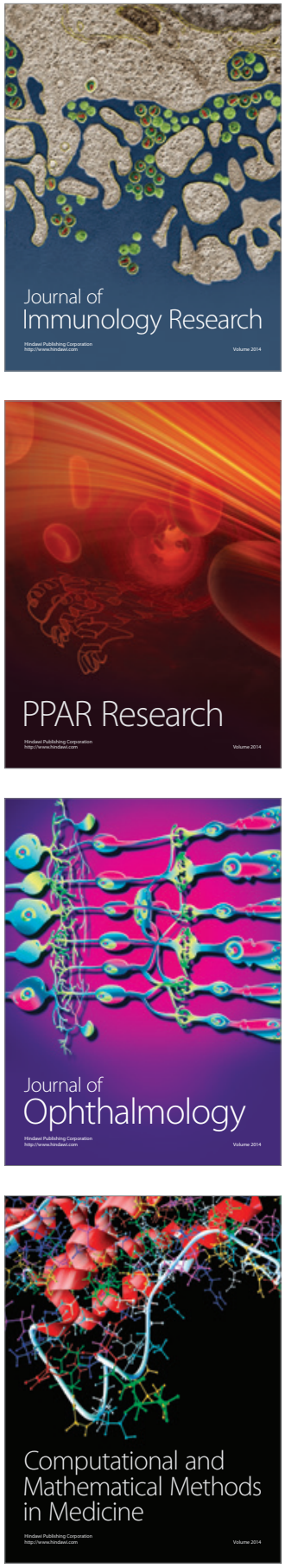

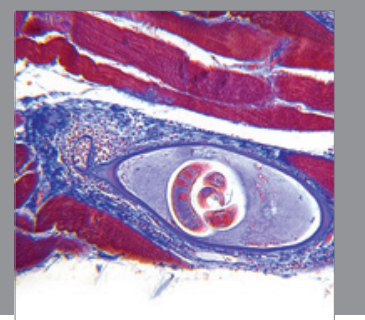

Gastroenterology

Research and Practice
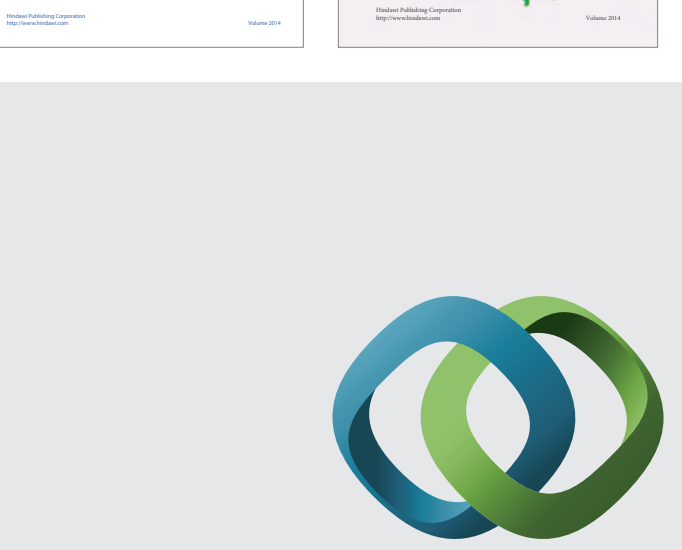

\section{Hindawi}

Submit your manuscripts at

http://www.hindawi.com
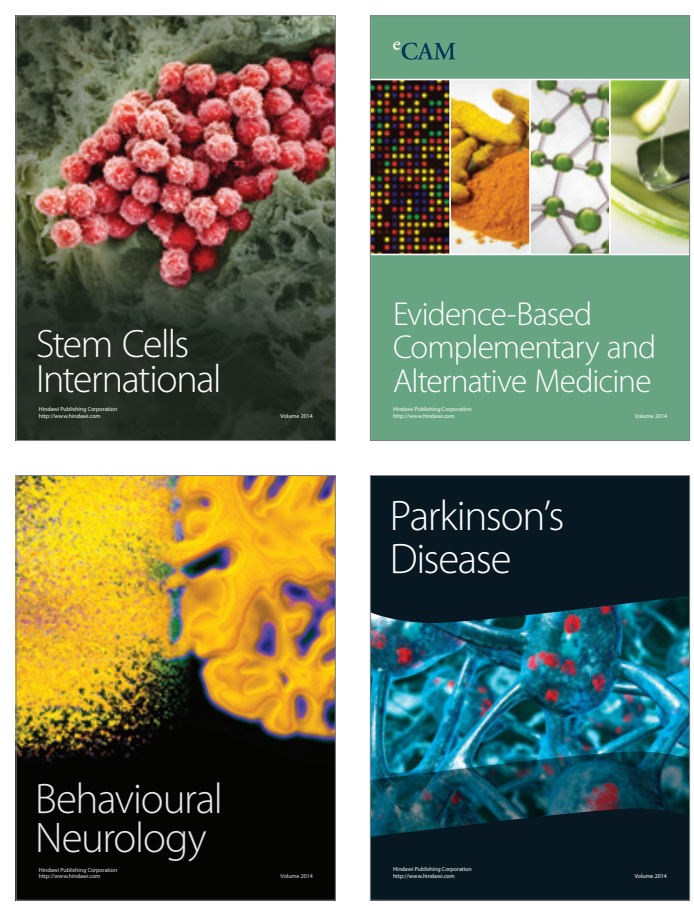

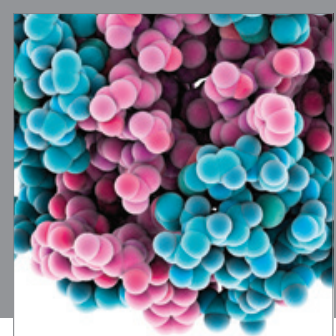

Journal of
Diabetes Research

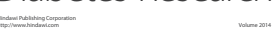

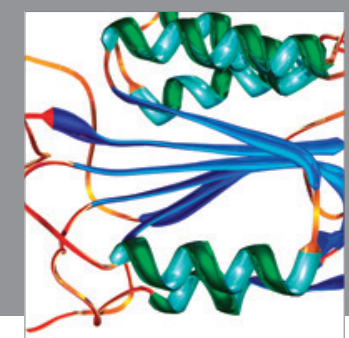

Disease Markers
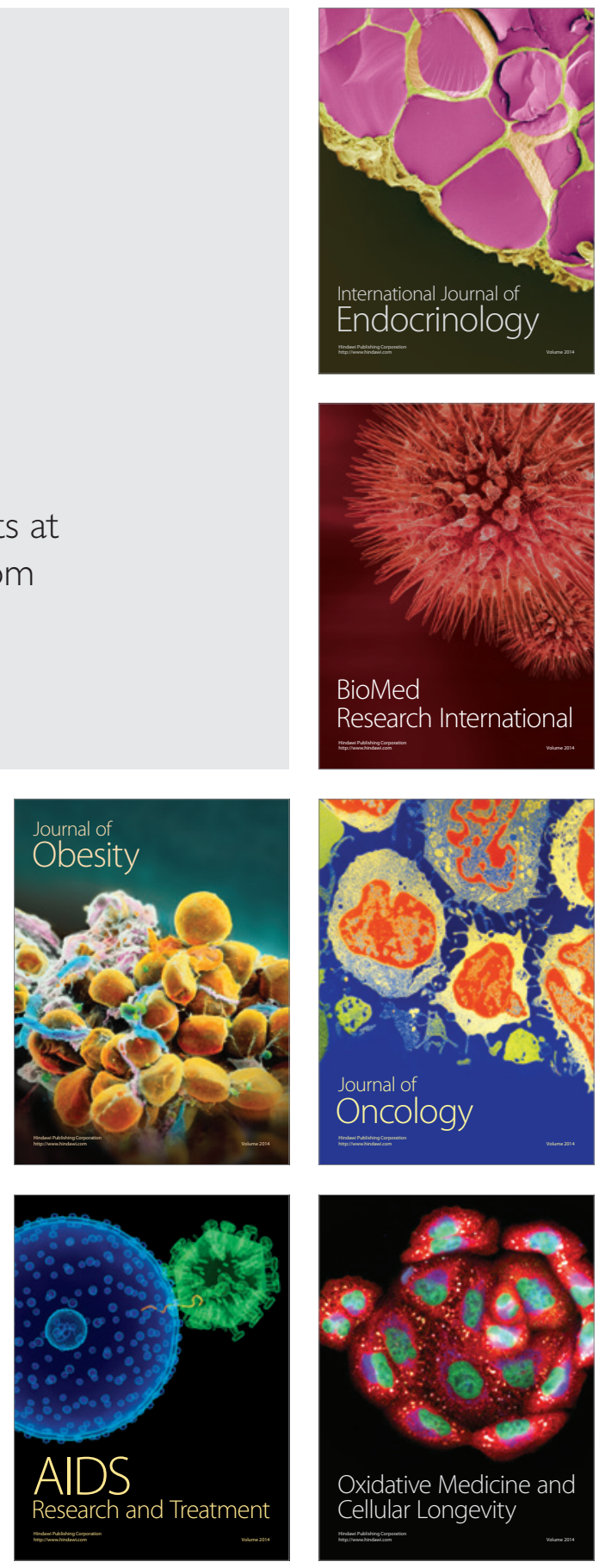